\title{
Racismo: criminalização e genocídio da população negra. Quando vamos começar a respirar?
}

\section{Racism: criminalization and black population genocide. When are we going to start breathing?}

\section{Lúcia Xavier*}

\begin{abstract}
Resumo - Esse artigo pretende refletir sobre os caminhos da luta contra o Racismo na contemporaneidade, especialmente nesse momento, atravessada pela pandemia do novo Coronavírus (Covid-19), onde as desigualdades raciais tornam-se mais evidentes, enquanto a sociedade permanece em silêncio face ao genocídio da população negra.

Palavras-chave: racismo; relações raciais; pandemia do novo Coronavírus (Covid-19); desigualdades raciais; genocídio da população negra.
\end{abstract}

\begin{abstract}
This article intends to reflect on the ways of the fight against Racism in contemporary times, especially at that moment, crossed by the pandemic of the new Coronavirus (Covid-19), where racial inequalities become more evident, while society remains silent in the face of genocide of the black population.

Keywords: racism; race relations; new Coronavirus (Covid-19) pandemic; racial inequalities; black population genocide.
\end{abstract}

\footnotetext{
*Assistente Social, graduada em Serviço Social pela Escola de Serviço Social da Universidade Federal do Rio de Janeiro (UFRJ). Fundadora e coordenadora de CRIOLA, organização de mulheres negras com sede no Rio de Janeiro. É membro do Comitê Mulheres Negras Rumo a um Planeta 50-50 em 2030, implementado por ONU Mulheres-Brasil. E-mail: luciaxavier@criola.org.br.
} 
Levou séculos para que o Estado brasileiro pudesse reconhecer a presença do racismo como fator estruturante das relações sociais no país. E isso só acontece agora - ao final do século XX início do século $X X I$ - como resultado de um trabalho longo, árduo, vivido em profundo isolamento por nós, negros. Enquanto denunciávamos o racismo; enquanto demonstrávamos a perversidade com que esse definia privilégios e exclusões, vidas e mortes; enquanto éramos nós mesmos nosso próprio testemunho, o restante da sociedade permanecia em silêncio.

Jurema Werneck, 2003

\section{Introdução}

A crise global de 2008 fez crescer em todas as partes do mundo movimentos conservadores baseados na supremacia branca contra os direitos humanos e contra a interferência dos Estados como regulador das relações sociais. Esses movimentos, atrelados a uma perspectiva ultraliberal, promovem mudanças globais igualmente conservadoras, varrendo de todas as partes governos de esquerda, considerados governos do atraso.

Nessa mesma linha, desde 2014, o Brasil vem sofrendo mudanças políticas, econômicas e sociais sem precedentes. Afetado pela crise econômica global de 2008, soma-se a ação judicial contra a corrupção na Petrobrás, denominada Operação Lava Jato, que trouxe para o centro das investigações membros do governo do Partido dos Trabalhadores (PT) e o ex-presidente Luiz Inácio Lula da Silva, posteriormente preso em 2018. Em 2016, Dilma Rousseff, presidente eleita em 2014, foi afastada do cargo após sofrer um processo de impeachment. Com a assunção do vice Michel Temer, vimos cair por terra um longo trabalho de redemocratização do país, desde o fim da ditadura militar.

O governo Temer reduziu e congelou os gastos nas áreas sociais (Emenda Constitucional no 95 - chamada pelos opositores de PEC da morte) e empreendeu reformas trabalhistas (Lei 13.467/2017) alterando e flexibilizando os dispositivos da Consolidação das Leis do Trabalho (CLT). O Governo Temer deixa como herança, austeridade e um rastro de corrupção que o levou à prisão em 2019 na Operação Lava Jato. Um ano depois, o ex-presidente é solto e cumpre medidas cautelares.

A crise acabou gerando um quadro de instabilidade política, que fez eclodir uma onda conservadora gestada desde 2003, a partir de setores insatisfeitos com a ascensão do Partido dos Trabalhadores ao poder. Esses setores não estavam interessados somente na mudança do comando dos poderes, os seus interesses também se alargavam para outros processos voltados para a mudança de paradigma dos direitos, do funcionamento do Estado e da ampliação do acesso sem barreiras aos bens comuns (água, terras, florestas etc.). Diante do esfacelamento do projeto político da esquerda, de uma crise econômica e financeira, de valores retrógrados e de constantes ataques aos direitos humanos, chega ao poder em 2019 o atual Presidente da República, Jair Messias Bolsonaro. 


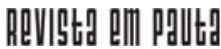

\} RACISMO: CRIMINALIZAÇÃO E GENOCÍDIO - XAVIER, L. \}

DOI: $10.12957 / R E P .2020 .52018$

O então Presidente inicia seu governo com um projeto político de enxugamento das funções do Estado em relação ao pacto de proteção social baseado em Direitos Humanos. Promove a reforma da previdência; o desregulamentação das terras e territórios de povos indígenas, de comunidades tradicionais - dentre elas as comunidades quilombolas; bem como do fim da proteção da floresta amazônica e de outras áreas de proteção ambiental.

O projeto em curso também almeja promover reformas em outros âmbitos, promovendo o desregulamento de políticas públicas e encerrando os parcos serviços oferecidos. Com uma estratégia de militarização dos postos governamentais, como forma de sustentação política e de controle, mais de 20 ministérios passam a ter em seu comando militares das forças armadas; inclusive alargando a participação dessas forças em ações de controle social nos estados. A forte militarização também vem acompanhada da flexibilização da legislação do uso de armas para civis, promessa de campanha do então Presidente, com a desculpa de promover a proteção dos cidadãos e cidadãs.

Faz parte desse projeto o ataque frontal aos grupos vulnerabilizados como a população negra, LGBTI, povos indígenas, mulheres. Os primeiros ataques desses setores dirigidos à população negra tiveram início ainda na campanha eleitoral e seguiram imediatamente a posse como presidente. O debate sobre a inexistência do racismo como causa estrutural das desigualdades raciais; as tentativas de desregulamentar direitos da população negra, como a política de cotas nas universidades; o não reconhecimento dos direitos trabalhistas das trabalhadoras domésticas; a criminalização dos negros, sobretudo dos jovens; o tratamento com inferioridade e a veiculação de imagens simbólicas de negros subordinados como a do deputado Hélio Fernando Barbosa Lopes (Hélio Bolsonaro), fazem parte do repertório perverso desses setores. Ainda no intuito de afirmar o desprezo pelo debate sobre a questão racial, o Presidente empossou, recentemente, Sérgio Camargo como presidente da Fundação Cultural Palmares. O órgão foi criado em 1988 e está voltado para estimular, integrar, preservar, proteger e disseminar as culturas negras; inclusive a de acompanhar o reconhecimento das comunidades quilombolas. Sérgio Camargo trata a questão racial como uma falsa questão, não acredita que existe racismo no país e chama o movimento negro de "escoria maldita"1.

As ações negativas voltadas para a população negra só reforçaram a violência, a morte e a negligência no enfrentamento às desigualdades ra-

\footnotetext{
1 O presidente da Fundação Cultural Palmares, Sérgio Camargo, "chama o movimento negro de 'escória maldita" "em uma reunião gravada sem que ele tivesse conhecimento. Disponível em: https://g1.globo.com/politica/noticia/2020/ 06/02/sergio-camargo-presidente-da-fundacao-palmares-chama-movimento-negro-de-escoria-maldita-emreuniao.ghtml. Acesso em: 02 jul. 2020.
} 


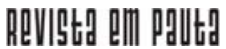

\} RACISMO: CRIMINALIZAÇÃO E GENOCÍDIO - XAVIER, L. \}

DOI: $10.12957 /$ REP.2020.52018

ciais. Dados apresentados pelo Monitor da Violência ${ }^{2}$ demonstram que o país teve 4.146 assassinatos em março de 2020, são 417 mortes a mais em comparação com o mesmo mês de 2019, uma alta de 11\% (G1, 2020a).

Em março de 2020 fomos acordados com a notícia de uma pandemia letal que assolava a Europa, provocada pelo novo Coronavírus (Covid19). A pandemia, que tem início na província de Wuhan na Cima, chega ao Brasil através dos viajantes de férias ou a trabalho da Europa, provavelmente da Itália. Em pouco tempo também registramos os primeiros casos no país. Fechamos o mês de maio de 2020 com 499.966 casos do novo Coronavírus (Sars-CoV-2) ${ }^{3}$, com 28.849 mortes.

Com a pandemia, medidas de quarentena e isolamento social são aplicadas em todas as cidades, especialmente São Paulo e Rio de Janeiro, excetuando os serviços essenciais - supermercados e farmácias, transporte e outros. A quarentena obrigatória, tinha como finalidade impedir o colapso nos serviços de saúde de alta complexidade e a imediata construção de hospitais de campanha que pudessem oferecer tratamento.

As medidas geraram uma imediata suspensão do emprego e desemprego, observa-se a falta de condições para o acesso a alimentação, sobretudo para aqueles que já viviam em extrema pobreza; o crescimento do adoecimento em diferentes grupos sociais e a falta de condições para a prevenção, a exemplo da falta de água para lavar as mãos, medida essencial de prevenção. A crise sanitária trouxe à tona a necessidade de tomar medidas para a proteção dos mais vulneráveis como idosos, encarcerados, moradores de favelas e periferias e população de rua. Promovendo assim um intenso debate em torno da garantia dos direitos humanos essenciais, diante das crises econômicas e sociais face à crise sanitária instalada com a pandemia.

Em menos de um mês, os grupos sociais, já vulnerabizados pela crise econômica e política, encaram outras crises de ordem sanitária, social e emocional. Medidas de enfrentamento a crise tem início no âmbito da sociedade e do legislativo com a campanha da renda mínima que acabou instituindo um auxílio emergencial de $\mathrm{R} \$ 600,00$ (seiscentos reais), durante três meses, para aquelas pessoas que não tinham renda para garantirem as mínimas condições de vida. O Programa de Auxílio emergência descortinou um contingente populacional em torno de 46 milhões de pessoas desprotegidas e invisíveis para o poder público. Nessa direção é também instituída ações de redistribuição de recursos financeiros para os estados e municípios, através do que convencionou-se chamar de "economia de guerra". Junto a

\footnotetext{
${ }^{2}$ Em matéria intitulada Mesmo com pandemia do coronavírus, Brasil tem alta de $11 \%$ no número de assassinatos em março, de acordo com o Monitor da Violência, uma parceria entre o G1, o Núcleo de Estudos da Violência da USP e o Fórum Brasileiro de Segurança Pública, que tem como objetivo discutir a questão da violência no país e apontar caminhos para combatê-la. Disponível em: https://g1.globo.com/monitor-da-violencia/noticia/2020/05/25/mesmo-compandemia-do-coronavirus-brasil-tem-alta-de-11 percent-no-numero-de-assassinatos-em-marco.ghtml. Acesso em: 02 jul. 2020.

${ }^{3}$ Sars-CoV-2 - Síndrome Respiratória Aguda Grave do Coronavírus 2.
} 


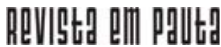

\} RACISMO: CRIMINALIZAÇÃO E GENOCÍDIO - XAVIER, L. \}

DOI: $10.12957 / R E P .2020 .52018$

essas e outras medidas, o Estado ativou os comandos militares para a segurança pública.

Na medida que a pandemia avançava, as perdas dos direitos começaram a tomar força, numa sociedade com profundas desigualdades e sem nenhuma participação da Presidência da República na condução e controle dos problemas sociais amplificados pela pandemia. A descrença pelo Presidente sobre os efeitos da pandemia na vida brasileira não era um posicionamento isolado. Como ele, diversos governantes em todas as partes do mundo também compreendiam esse impacto como algo forjado contra os seus governos. Poucos voltaram atrás como o presidente dos Estados Unidos, Donald Trump. E no caso brasileiro, esse processo só inflamou a crise política entre os poderes instituídos, em especial com o Supremo Tribunal Federal, que tem arbitrado em todas as ações do Executivo.

Entre os conflitos gerados nos processos de crises, um tema chama a atenção para além do descaso no trato governamental com as mortes causadas pela pandemia, é a questão racial. As crises políticas, sociais, econômicas e sanitárias evidenciaram com tamanha nitidez as desigualdades raciais a ponto de demonstrar que nesse momento a população negra é a mais afetada, inclusive com uma forte violência perpetrada pelo Estado, especialmente pelas polícias militares. Não por coincidência, o mesmo ocorre nos Estados Unidos, onde os negros são igualmente afetados e sofrem profunda violência do Estado.

A pandemia atingiu inicialmente uma população com condições muito favoráveis e foi dura mesmo neste grupo de pessoas brancas, ricas e com amplo acesso à saúde. Com a ampliação da contaminação para outros grupos, verificamos que ao desagregar os casos por raça/cor, mesmo em menor número, a população negra sofreu maior impacto. De 30 mil casos notificados como Síndrome Respiratória Aguda Grave (SRAG), confirmadas para COVID-19, analisados pelo Núcleo de Operações e Inteligência em Saúde (NOIS, 2020), a diferença na taxa de óbitos entre negros (55\%) e brancos (38\%) é assustadora. ${ }^{4}$

"I Can't Breathe!" ("Não consigo respirar"). Em 25 de maio de 2020, vimos pelas reportagens transmitidas na televisão e nas redes sociais, a polícia de Minneapolis em Minnesota, Estados Unidos, matar por sufocamento George Floyd. A imagem resgatou à memória a morte de Eric Garner, ocorrida em 2014, nas mesmas condições que a de Floyd, que também implorou por sua vida avisando que não conseguia respirar.

\footnotetext{
${ }_{4}^{4} 11^{\text {a }}$ Nota Técnica (NT), o Núcleo de Operações e Inteligência em Saúde (NOIS), liderado pelo Departamento de Engenharia Industrial do Centro Técnico Científico da PUC-Rio (CTC/PUC-Rio). O estudo destaca que conforme os registros do Ministério da Saúde, quase dez mil se identificaram como brancos e quase nove mil como pretos e pardos. Apesar da proximidade dos números, ao avaliar os óbitos, as diferenças se evidenciam: quase $55 \%$ dos pretos e pardos faleceram, enquanto entre os brancos, esse valor ficou em 38\%. Disponível em: http://www.ctc.puc-rio.br/ diferencas-sociais-confirmam-que-pretos-e-pardos-morrem-mais-de-covid-19-do-que-brancos-segundo-nt11-donois/. Acesso em: 02 jul. 2020.
} 


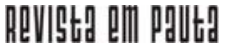

\} RACISMO: CRIMINALIZAÇÃO E GENOCÍDIO - XAVIER, L. \}

DOI: $10.12957 /$ REP.2020.52018

George Floyd, que trabalhava como segurança, foi preso na saída de uma loja, acusado de passar uma nota falsa de 20 dólares. ${ }^{5} \mathrm{Na}$ mesma ocasião, foram assassinados pela polícia militar 17 jovens na região metropolitana do Rio de Janeiro, dentre eles João Pedro Mattos Pinto. O adolescente de 14 anos foi morto a tiros na cidade de São Gonçalo no Rio de Janeiro. Foram 70 tiros em direção à sua casa em uma diligência policial na região. A família de João Pedro percorreu por 24 horas hospitais, instituto de medicina legal e delegacias para saber do paradeiro do corpo do filho, até encontrá-lo morto.

No Brasil, a cada 23 minutos morre um jovem negro, são 63 mortos por dia, 23.100 no período de 2018. Eles geralmente estão na faixa etária entre 14 a 29 anos e, em sua maioria, são mortos sem nenhuma resistência física ou armada. ${ }^{6}$

O desencadeamento de manifestações públicas contra a morte, especialmente pelo movimento Black Lives Matter (Vidas Negras Importam $)^{7}$, possibilitou a prisão dos policiais que o mataram e a mudança no procedimento da conduta policial e, quem sabe, da política de segurança em todo mundo. O Movimento Black Lives Matter (Vidas Negras Importam) surge em 2013, depois da absolvição de George Zimmermann que matou a tiros o adolescente Trayvon Martin nos Estados Unidos. No Brasil, jovens negros também foram às ruas por João Pedro e por Floyd. A Coalizão Negra por Direitos, rede com mais de 150 organizações negras, promoveu uma manifestação virtual contra a morte de João Pedro e por tantas outras mortes que ocorrem todos os dias. Mortes provocadas pelo Estado que não incomodam a sociedade brasileira.

Em pleno século XXI a sociedade brasileira ainda permanece em silêncio quando o tema é racismo e seus impactos na população negra. $\mathrm{O}$ caráter de invisibilidade e minimização desses impactos faz parte dos arranjos políticos-ideológicos vigentes nessas práticas. Mesmo depois do fim da escravidão e com o advento do regime republicano, a sociedade brasileira se recusa a reconhecer o racismo como fator estruturante das relações sociais e das desigualdades raciais, a ponto de estabelecer o mito da democracia racial, mais tarde desmascarado pelos movimentos negros. Ignora o geno-

\footnotetext{
${ }^{5}$ Fonte: https://pt.wikipedia.org/wiki/Assassinato_de_George_Floyd. Acesso em: 02 jul. 2020.

${ }^{6}$ SENADO FEDERAL. Relatório Final da Comissão Parlamentar de Inquérito do Assassinato de Jovens (CPIADJ). Criada pelo Requerimento n⿳0 115, de 2015, de autoria da Senadora Lídice da Mata (PSB/BA). Relator: Senador Lindbergh Farias (PT/RJ). Brasília, 2020. Disponível em: https://www12.senado.leg.br/noticias/arquivos/2016/06/08/veja-a-integrado-relatorio-da-cpi-do-assassinato-de-jovens. Acesso em: 02 jul. 2020.

7 "O Movimento Black Lives Matter Foundation "é uma organização global nos EUA, Reino Unido e Canadá, cuja missão é erradicar a supremacia branca e construir poder local para intervir na violência infligida às comunidades negras pelo Estado e pelos vigilantes. Ao combater atos de violência, criando espaço para a imaginação e a inovação dos negros e centralizando a alegria dos negros, estamos obtendo melhorias imediatas em nossas vidas." (Tradução livre). Disponível em: https://blacklivesmatter.com/. Acesso em: 02 jul. 2020.
} 


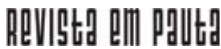

\} RACISMO: CRIMINALIZAÇÃO E GENOCÍDIO - XAVIER, L. \}

DOI: $10.12957 / R E P .2020 .52018$

cídio $^{8}$ em curso para obter as vantagens que o racismo proporciona aos brancos.

Segundo a Convenção para a Prevenção e Repressão do Crime de Genocídio (1951), em seu Artigo 2oㅜ

entende-se por genocídio qualquer dos seguintes atos, cometidos com a intenção de destruir no todo ou em parte, um grupo nacional, étnico, racial ou religioso, como tal: a) matar membros do grupo; b) causar lesão grave à integridade física ou mental de membros do grupo; c) submeter intencionalmente o grupo a condição de existência capazes de ocasionar-Ihe a destruição física total ou parcial; d) adotar medidas destinadas a impedir os nascimentos no seio de grupo; e) efetuar a transferência forçada de crianças do grupo para outro grupo.

Em outras palavras, a situação vivida pela população negra pode ser entendida como atos genocidas, mesmo sem declaração pública de autoridades sobre essa intencionalidade. Então vejamos: o assassinato de jovens negros; as lesões graves à integridade física e emocional de crianças a adultos negros e negras face aos ambientes hostis e de constante humilhação e violência; os ataques as casas de religião de matriz africana; a submissão à pobreza e à extrema pobreza de milhões de negros e negras que se alimentam uma vez por dia sem segurança alimentar e nutricional; a falta de cidadania e de segurança no mundo do trabalho; o analfabetismo; o encarceramento em massa de homens e mulheres negros; os níveis elevados de mortalidade materna entre outros indicadores.

A luta contra o Racismo no Brasil, portanto, tem como objetivo erradicar o projeto genocida em curso desde quando a primeira pessoa negra chegou nesse país na condição de escravo. Essa luta nunca foi a de flexibilizar para poucos os parcos direitos disponíveis. E sim a de garantir condições de igualdade e de oportunidades para todos os grupos sem distinção. Mas, o projeto de morte, impede o estabelecimento de qualquer negociação que garanta direitos iguais para a população negra de modo duradouro e permanente.

Já no período da escravidão, ações políticas de todos os modelos explodiram nas cidades e no país, buscando consolidar um caminho rumo a igualdade racial. Primeiro a luta pela liberdade e junto com ela, o direito à vida, ao trabalho, à saúde. A história demonstra que todas as ações, que buscaram o reconhecimento da condição de humanidade e da igualdade entre os grupos raciais, em 132 anos após o fim da escravidão, foram combatidas de diferentes formas em todas as instâncias públicas e privadas. E mais recentemente, mesmo quando a correlação de forças na sociedade

\footnotetext{
${ }^{8}$ Decreto ${ }^{\circ}$ 30.822, de 6 de maio de 1952. Promulga a Convenção para a Prevenção e a Repressão do Crime de Genocídio, concluída em Paris, a 11 de dezembro de 1948, por ocasião da III Sessão da Assembleia Geral das Nações Unidas. Disponível em: http://www.planalto.gov.br/ccivil_03/Atos/decretos/1952/D30822.html. Acesso em: 02 jul. 2020.
} 


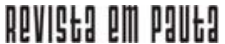

\} RACISMO: CRIMINALIZAÇÃO E GENOCÍDIO - XAVIER, L. \}

DOI: $10.12957 /$ REP.2020.52018

apresentava maiores condições para o estabelecimento de mecanismos de direitos iguais, em consonância com o espírito cidadão da Constituição Federal promulgada em 1988, foram rechaçadas, minimizadas ou combatidas.

Esse artigo pretende refletir sobre os caminhos da luta contra o Racismo na contemporaneidade, especialmente nesse momento, atravessada pela pandemia do novo Coronavírus (Covid-19), em que as desigualdades raciais tornam-se mais evidentes, enquanto que a sociedade permanece em silêncio face ao genocídio da população negra.

\section{Estratégias de luta contra o Racismo}

A escultura Ainda a Lamentar ${ }^{9}$, da artista visual Rosana Paulino ${ }^{10}$, traduz o significado dessas vantagens e os esforços que a população negra tem realizado contra o racismo. A escultura de barro de uma mulher negra, sem braços puxando com o seu corpo diferentes objetos, dentre eles um homem branco em pé sobre o que ela precisa carregar. Para a artista, a falta dos braços representa a falta de instrumentos. E é com essa imagem que precisamos analisar as relações raciais no Brasil e suas consequências. A imagem representa simbolicamente a população negra que tem, mesmo sem condições, lutado para romper com os efeitos do racismo, sem aliança com nenhum setor da sociedade brasileira.

Os marcos da luta antirracista no Brasil contemporâneo datam da década de 1970. Momento igualmente importante para o crescimento de ações cidadãs no país, especialmente contra a ditadura militar vigente no período. É nesse contexto que organizações e movimentos sociais surgiram como uma nova perspectiva metodológica e política de mudança de paradigmas para o acesso a bens e serviços baseados em direitos, e para a consolidação de um regime democrático de fato.

É nesse período que também crescem os processos de denúncia e organização de grupos e núcleos de negros e negras contra o racismo, fortalecidos por uma onda transformadora dos padrões políticos, econômicos e sociais internacionais e brasileiros da época. Imbuídos do clamor por justiça contra violência, negros e negras saem às ruas para denunciar a violência racial, em especial a policial. O Movimento Negro encontra eco nos movimentos pelos direitos civis para negros nos Estados Unidos, pela libertação das colônias africanas, especialmente Angola e Moçambique, e pela luta contra o Apartheid na África do Sul.

\footnotetext{
${ }_{9}^{9}$ Obra de 2011 ; em cerâmica, cordão, madeira, plástico e metal.

${ }^{10}$ Doutora em Artes Visuais pela Escola de Comunicação e Artes da Universidade de São Paulo (ECA/USP). Especialista em gravura pelo London Print Studio, de Londres, e Bacharel em gravura pela ECA/USP. Conforme descrito em seu site, a artista vem se destacando por sua produção ligada a questões sociais, étnicas e de gênero. Seus trabalhos têm como foco principal a posição da mulher negra na sociedade brasileira e os diversos tipos de violência sofridos por esta população decorrente do racismo e das marcas deixadas pela escravidão.

Disponível em: http://www.rosanapaulino.com.br/trabalhos/. Acesso em: 02 jul. 2020.
} 


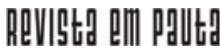

\} RACISMO: CRIMINALIZAÇÃO E GENOCÍDIO - XAVIER, L. \}

DOI: $10.12957 /$ REP.2020.52018

No Brasil, intelectuais ligados às pesquisas financiadas pela UNESCO (1950) e CEPAL (1960) e negros inspirados na luta contra o racismo e a favor da libertação africana ${ }^{11}$ apresentaram teorias explicativas sobre os efeitos do racismo nas classes trabalhadoras, somam-se a essas leituras as dimensões de gênero, já presentes no debate do feminismo, sobretudo do feminismo negro. Chegamos então ao fim da ditadura militar com uma reforma constitucional e de ampliação da participação de outros setores sociais alinhados com uma perspectiva progressista e de defesa dos direitos.

A reforma da Constituição Federal, mais que disputa dos grupos sociais, surge como uma promessa de mudanças profundas no Brasil. Vimos surgir um espaço novo de pactuação onde nada e ninguém ficaria de fora. Espelha-se aí impedimentos de ações autoritárias e conquistas de direitos ainda não experienciados, sobretudo por nós, negros e negras, cujos direitos seguiam negados. A Constituição passa, então, a garantir a igualdade de direitos sem distinção de raça, cor, credo, gênero, religião; a criminalizar o Racismo; a reconhecer e a garantir a titulação das terras quilombolas; a reconhecer e promover a proteção ao trabalho doméstico, em que pese que sem a garantia de todos os direitos trabalhistas vigente à época.

Passados 32 anos após a promulgação da Constituição Federal Brasileira (1988), aposta política de diferentes setores sociais para as mudanças estruturais brasileiras, as dimensões de igualdade e de igualdade de oportunidades não se concretizaram. As desigualdades e destituição de direitos baseadas em raça/cor, seguiram seu curso. Enquanto a vida seguia, também seguiam as mudanças nos mecanismos de exploração e subordinação geradores de exclusão e de morte.

Durante esse período foram vários os esforços dos Movimentos de Negros e de Mulheres negras para denunciar o racismo e as desigualdades; bem como para ampliar e consolidar direitos para a população negra. Muitos deles foram a base da construção de políticas públicas e legislações nacionais. Embora, durante esse período, foram muitas as ações políticas desenvolvidas, inclusive campanhas contra a esterilização em massa e contra o extermínio de crianças e adolescentes, destaco aqui alguns desses esforços não só pelo seu simbolismo, mas também pelos efeitos na Sociedade, no Estado e nos processos de luta contra o racismo: o enfrentamento do mito da "democracia racial"; a Marcha dos 100 Anos Contra a Farsa de Abolição (1988) ${ }^{12}$; atuação no processo de redemocratização do Brasil e na reforma da Constituição Brasileira; o I Encontro Nacional de Mulheres Negras (1988); a implantação do GTI-Grupo de Trabalho Interministerial (1995); a Conferência de Durban (2001); a política de cotas nas univer-

\footnotetext{
${ }_{11}$ A questão racial no Brasil dos anos 50. CPDOC/FGV. Disponível em: https://cpdoc.fgv.br/producao/dossies/ AEraVargas2/artigos/SegundoGoverno/QuestaoRacial. Acesso em: 02 jul. 2020.

12 Para mais informações, ver: ABREU, R. B. A Marcha Contra a Farsa da Abolição na Transição Democrática (1988). Revista Contemporânea. Ano 4, n. 5, 2005. Disponível em: http://www.encontro2014.rj.anpuh.org/resources/anais/ 28/1393170298_ARQUIVO_AMarchaContraaFarsadaAbolicaonaTransicaoDemocratica.pdf. Acesso em: 01 maio 2020.
} 


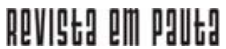

\} RACISMO: CRIMINALIZAÇÃO E GENOCÍDIO - XAVIER, L. \}

DOI: $10.12957 /$ REP.2020.52018

sidades e a criação da SEPPIR em 2003. São esses marcos políticos que resumidamente analisaremos aqui para deixar evidente que ações contra o projeto de morte tem sido reiteradamente combatidas. E também para entender o alcance das estratégias desenvolvidas nesse período, buscando indicativos dos novos processos políticos face ao reiterado ataque a população negra nos dias atuais.

Começo então destacando a estratégia de denúncia do mito que encerrava a ideia de democracia racial. O mito da democracia racial foi uma ideologia política que pregava a harmonia, a vivência pacífica e tolerante entre os diferentes grupos raciais no país. Já que as tentativas de embranquecimento da população negra através dos projetos políticos eugênicos não obtiveram êxito.

O mito também foi uma das bases ideológicas da ditadura militar de 1964 (PIRES, 2018) denunciada pelo Movimento Negro nas décadas de 1970 e que segue sendo combatido até os dias atuais. A ditadura militar e empresarial (1964) utilizou o mito para escamotear a violência e o controle da população negra; infiltrando-se nas organizações da época. Nesse período, a violência policial e as ações de grupo de extermínio também cumpriam esse papel. Thula Rafaela Oliveira Pires (2018) ressalta que:

Dentro da Doutrina de Segurança Nacional da época, além da negrada representar um perigo interno à ordem pública, havia efeitos externos indesejados pelo regime nesse processo de articulação. No plano internacional, interessava ao Brasil blindar-se da interferência de organizações relacionadas à proteção de direitos humanos que, no que diz respeito especificamente à questão racial, estavam bastante atentas aos processos de independência africanos, movimento por direitos civis nos EUA e regimes instituídos de apartheid como o da África do Sul. (p. 1061).

E segue em suas reflexões demonstrando o inequívoco uso do mito como fator de manutenção das estruturas racistas de controle e subordinação das populações negras. A autora destaca que:

Ao assumir o mito da democracia racial como uma de suas bases ideológicas, a ditadura empresarial-militar garantia, de um lado, que fosse intocado o modelo de supremacia branca e os privilégios a ele decorrentes; de outro, sufocava qualquer possibilidade de enfrentamento direto da população não branca sobre as violências sofridas: 'Falar de racismo, e de seu enfrentamento, é sempre inoportuno. Nunca é a hora nem o lugar, no caso brasileiro' (CARDOSO, 2017b). (p. 1062).

A ideia de que o Brasil tinha alcançado um patamar democrático racial, encobriu, e ainda encobre, as desigualdades, as discriminações e a violência sofrida, especialmente aquela perpetrada pelo Estado Brasileiro. 


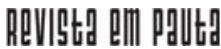

\} RACISMO: CRIMINALIZAÇÃO E GENOCÍDIO - XAVIER, L. \}

DOI: $10.12957 /$ REP.2020.52018

Processos que alijaram negros e negras da participação social e da liberdade; impedindo o acesso a quaisquer direitos, quer seja no campo civil e político ou no campo econômico, social, cultural e ambiental.

As desigualdades geradas são de tamanha profundidade que precisaria de muitos anos de investimentos para equiparar socioeconomicamente, ainda em condições mínimas, negros e brancos. Estudos realizados no campo da Educação evidenciam essas disparidades. No estudo desenvolvido por Ricardo Henriques (2002) sobre raça e gênero no sistema de ensino, observou-se que as disparidades educacionais atravessaram gerações.

Ao analisarmos os níveis de escolaridade a partir do recorte racial, constatamos que a escolaridade média de um jovem negro com 25 anos de idade gira em torno de 6,1 anos de estudo; um jovem branco da mesma idade tem cerca de 8,4 anos de estudo. O diferencial é de 2,3 anos de estudo. A intensidade dessa discriminação racial, expressa em termos da escolaridade formal dos jovens adultos brasileiros, é 40 extremamente alta, sobretudo se lembramos que trata-se de 2,3 anos de diferença em uma sociedade cuja escolaridade média dos adultos é em torno de 6 anos. Embora a diferença entre nossos jovens brancos e negros de uma mesma cohorte (faixa geracional) seja intensa, não é somente a magnitude dessa diferença que representa um elemento perturbador da discriminação observada. Em termos do projeto de sociedade que o país está construindo, o mais inquietante é a evolução histórica e a tendência de longo prazo dessa discriminação. Apesar da escolaridade média de brancos e negros crescer de forma contínua ao longo do século XX, a diferença de 2,3 anos de estudo entre jovens brancos e negros de 25 anos de idade é a mesma observada entre os pais desses jovens. $E$, de forma assustadoramente natural, 2,2 anos de estudo é a intensidade da diferença entre os avós desses jovens. (p. 39).

A denúncia de que o Brasil não era uma democracia racial, revelou o isolamento político de negros e negras pelos setores sociais, inclusive os mais sensíveis às causas sociais. Nem a luta contra a ditadura militar possibilitou a incorporação da luta contra o racismo na agenda política dos setores progressistas. As lutas sociais do período tinham como ponto de partida a exploração pelo sistema capitalista da força de trabalho. Nesse sentido o sujeito político primordial era a classe trabalhadora, único sujeito que poderia transformar essa realidade, através da luta de classes contra o sistema opressor e pelo fim da pobreza. A questão racial não era compreendida como estruturante das desigualdades e da violência perpetrada contra a população negra; e nem tão pouco era questionada como parte do sistema opressor para obtenção de vantagens e de acúmulo de bens e serviços. Portanto, a denúncia do mito deixou visível as vantagens obtidas por diferentes setores da sociedade, através da perpetuação dessas práticas. E pôde instituir em termos ideológicos uma identidade "negra", a partir do estabelecimento da "consciência negra". Instituindo o dia de morte do herói 


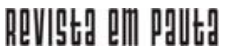

\} RACISMO: CRIMINALIZAÇÃO E GENOCÍDIO - XAVIER, L. \}

DOI: $10.12957 /$ REP.2020.52018

negro Zumbi dos Palmares, 20 de novembro, o Dia da Consciência Negra, mobilizador de ações contra o racismo em todo o país.

Com a estratégia do desmascaramento do mito, chegamos em 1988, ano em que se completou 100 anos desde a abolição da escravidão no país. O Movimento Negro responde a intenção de comemoração festiva com uma marcha contra o racismo. A Marcha dos 100 Anos Contra a Farsa da Abolição (1988) contou com a participação de 5.000 negros e negras e encontrou em seu percurso tanques de guerra do Exército Brasileiro. A Marcha teve início na Igreja da Candelária e deveria seguir por toda a Avenida Presidente Vargas até o busto de Zumbi na Praça XI, próximo à Central do Brasil, Rio de Janeiro, passando pelo túmulo de Duque de Caxias. Ameaçados, o Comando Militar do Leste não permitiu que os manifestantes chegassem ao busto do Herói negro Zumbi. A força apresentada em tanques de guerra e soldados armados foi uma reação descomunal ao tamanho da própria manifestação, mesmo tendo nesse ato mais um golpe ao mito da democracia racial e na própria dinâmica de transição democrática, no ano da reforma constitucional.

A Marcha não é somente um momento de protesto contra o mito, mas inaugura novas articulações que culminaram já na década de 1990 com a principal rede de organizações negras do Brasil, a Coordenação Nacional de Entidades Negras - CONEN. Ainda em 1988, o Movimento Negro começa a conviver com o Movimento de Mulheres Negras que, rompidas com o Movimento Feminista, iniciam a constituição de um movimento novo, híbrido, em que as dimensões de raça e gênero passam a ser orientadores da luta. Nasce então um novo sujeito político, herdeiro de diversas lutas, mas com um só propósito, lutar contra o racismo patriarcal, a partir da liderança das mulheres negras.

Nesse momento de efervescência, os Movimentos Negro e de Mulheres Negras seguem para a efetivação de uma das mais importantes estratégias para o enfrentamento do racismo no país, que foi a reforma da Constituição Federal. A reforma constitucional era também a principal estratégia da esquerda brasileira em prol das mudanças estruturais anunciadas em suas agendas políticas. Ainda solitários os Movimentos Negros e de MuIheres Negras, conseguiram garantir na Constituição reformada a inclusão do Racismo como crime inafiançável e imprescritível, como cláusula pétrea. Além disso, incluiu nas Disposições Transitórias, o reconhecimento e a titulação das terras quilombolas, dentre outros direitos. Alcançar a possibilidade de incluir o Racismo e suas práticas como crime na Constituição foi fundamental para mudar o patamar de lutas após a reforma.

Novas articulações para constituição de leis ordinárias, participação em espaços de delineamento de políticas públicas, sobretudo no campo da Educação e da Saúde, traz novos desafios para os Movimentos e obriga também a presença de militância especializada. Muito embora são os movimentos que pautam a ação, aqui surge as organizações não 


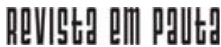

\} RACISMO: CRIMINALIZAÇÃO E GENOCÍDIO - XAVIER, L. \}

DOI: $10.12957 / R E P .2020 .52018$

governamentais negras que assumiram essa interlocução junto com os Movimentos.

Nos anos subsequentes, após novas manifestações públicas e ação de negros e negras nos partidos, ampliaram-se a participação de negros e negras na formulação de políticas públicas, a exemplo do Grupo de Trabalho Interministerial-GTI (1995) durante o mandato do ex-presidente Fernando Henrique Cardoso. Cabe destacar que a Marcha Zumbi contra o Racismo, pela Igualdade e pela Vida, ocorrida em Brasília, no dia 20 de novembro de 1995, que contou com mais de 30 mil manifestantes, desencadeou a instituição do Grupo de Trabalho Interministerial para a Valorização da População Negra (GTI). De acordo com o Decreto Presidencial, o GTI tinha como finalidade o desenvolvimento de políticas para a valorização da População Negra, através da articulação de diferentes ministérios. As suas atribuições eram:

(...) propor ações integradas de combate à discriminação racial, visando ao desenvolvimento e à participação da População Negra; elaborar, propor e promover políticas governamentais antidiscriminatórias e de consolidação da cidadania da População Negra; estimular e apoiar a elaboração de estudos atualizados sobre a situação da População Negra; reunir, sistematizar, avaliar e divulgar informações relevantes para o desenvolvimento da População Negra; incentivar e apoiar ações de iniciativa privada que contribuam para o desenvolvimento da População Negra; estabelecer diálogo permanente com instituições e entidades, incluídas as do movimento negro, nacionais e internacionais, cujos objetivos e atividades possam trazer contribuições relevantes para as questões da População Negra e seu desenvolvimento; estimular os diversos sistemas de produção e coleta de informações sobre a População Negra; contribuir para a mobilização de novos recursos para programas e ações na criação de mecanismos eficientes e permanentes na defesa contra o racismo e em áreas de interesse da População Negra, a fim de sugerir prioridade para otimizar sua aplicação; estimular e apoiar iniciativas públicas e privadas que valorizem a presença do negro nos meios de comunicação; examinar a legislação e propor as mudanças necessárias, buscando promover e consolidar a cidadania da População Negra; e, estabelecer mecanismos de diálogo e colaboração com os Poderes Legislativo e Judiciário, com o propósito de promover a cidadania da População Negra."

O GTI não durou muito para a efetivação das políticas públicas desenhadas por ele. Mas, deixou muitas pistas que foram desenvolvidas mais adiante, a exemplo de uma política voltada para a saúde da população negra ou mesmo a constituição de processos de regaste dos saberes, da história e da memória negra no país. Em que pese a sua pouca força política para engendrar internamente as políticas públicas nas estruturas governamentais, o GTI servirá mais tarde de modelo, em termos de atribuições e 


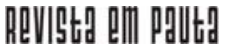

\} RACISMO: CRIMINALIZAÇÃO E GENOCÍDIO - XAVIER, L. \}

DOI: $10.12957 /$ REP.2020.52018

metodologias de trabalho, para a implementação da Secretaria de Políticas de Promoção da Igualdade Racial (SEPPIR, 2003).

A criação da Secretaria Especial de Políticas de Promoção da Igualdade Racial (SEPPIR) foi um passo significativo para a inclusão da questão racial nas estruturas de governo. O seu caráter articulador das ações dos outros ministérios; bem como a constituição de fonte de recursos orçamentários para o desenvolvimento de ações próprias de enfrentamento ao racismo, sobretudo o institucionalizado, foi o maior passo da agenda antirracista desse período.

Inspirada nos resultados promissores da III Conferência Mundial contra o Racismo, a Discriminação Racial, a Xenofobia e as Formas Correlatas de Intolerância, realizada em Durban, na África do Sul, em 2001, os documentos aprovados pela Conferência indicavam como uma possibilidade de erradicação do racismo e das desigualdades raciais, a aplicação de políticas de Ações Afirmativas em todos os níveis, considerando também outras formas agravadas de discriminação, tais como gênero, orientação sexual, idade e geração, entre outras.

Os resultados de Durban receberam um duro golpe logo imediatamente ao fim da Conferência. $\mathrm{O}$ ataque às torres gêmeas em Nova York, Estados Unidos, pelo grupo Al Qaeda. O ataque renovou o posicionamento racista de diferentes países que imediatamente desprezaram os acordos assinados, como assinala Jurema Werneck $(2005)^{13}$.

A despeito dos conflitos internos contra os resultados de Durban, os Movimentos Negros e de Mulheres Negras utilizaram esses documentos como norteadores para a reinvindicação de direitos e no delineamento de políticas públicas. Um dos temas mais debatidos nesses tempos foi o da Educação, em que pese que o campo da Saúde também se mostrou exitoso no que se refere a implementação de ações de enfrentamento do racismo institucionalizado e a implementação de uma política de saúde com equidade.

Todas as iniciativas de negociação política por direitos foram acompanhadas por denúncias através das manifestações dos movimentos. Em 2005 foi realizada a 2a Marcha Zumbi dos Palmares pela Vida, com maior preponderância das organizações de mulheres negras para reivindicar os nossos direitos e cobrar do Estado os compromissos assumidos há 10 anos atrás na 1a Marcha em 1995. O principal mote desta Marcha era a luta contra a violência que provocava um verdadeiro genocídio da população negra, atingindo especialmente os jovens negros.

O debate sobre as políticas de Ações Afirmativas no Brasil vem de longa data e começa a tomar corpo nos anos de 1990. Mas, ao ganhar fôlego após a III Conferência, diferentes setores da sociedade brasileira

${ }^{13}$ WERNECK, J. A luta continua: O combate ao racismo no Brasil pós-Durban. Revista do Observatório da Cidadania n. 55, 2005; p. 65. Disponível em: http://www.socialwatch.org/sites/default/files/pdf/en/panorbrasileirod2005_bra.pdf. Acesso em: 01 maio 2020. 


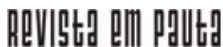

\} RACISMO: CRIMINALIZAÇÃO E GENOCÍDIO - XAVIER, L. \}

DOI: $10.12957 /$ REP.2020.52018

saíram do silêncio e assumiram uma posição contrária a um dos mecanismos de promoção da igualdade, as cotas nas universidades públicas. Intelectuais ${ }^{14}$ se posicionaram contrários às Políticas de Ação Afirmativas, especialmente no momento que diferentes setores questionavam a constitucionalidade desses mecanismos junto ao Supremo Tribunal Federal (STF). O posicionamento desses setores corroborava com a ideia de que a desigualdade enfrentada pela população negra era de caráter de classe. E que eles deveriam ser utilizados para enfrentar a pobreza como causa das iniquidades vividas por essa população. Os argumentos só fortaleciam o mito da democracia racial, reforçando a ideia de que os processos de empobrecimento são os responsáveis pelo não acesso aos direitos.

A primeira universidade a implantar o sistema de cotas foi a Universidade do Estado do Rio de Janeiro (UERJ), em 2002. Em seguida diferentes instituições iniciaram a implementação da política conforme a correlação de forças local. Em nenhuma instituição a implantação da política foi pacífica e unânime. O debate sobre essa política também trazia à tona a ausência de negros e negras no corpo discente da graduação e da pósgraduação; bem como, a falta de referência e de produção científica negra na formação universitária.

Uma vitória no Supremo Tribunal Federal contra o Partido dos Democratas (DEM), diminuiu as investidas contra as políticas de cotas, ao torná-las constitucionais e reconhecê-las como mecanismo de efetivação do direito a formação de nível superior. Isso não obriga de imediato a implantação das cotas nas instituições de ensino na graduação e pós, mas permite o debate entre os grupos interessados e as instituições. Após quase 18 anos de implementação das cotas nas universidades, os questionamentos dos seus resultados seguem, em que pese que o aproveitamento dos alunos e alunas é bastante superior, diante dos problemas e da falta de suporte institucional para o desenvolvimento educacional.

Por fim, e não menos importante, em 2010 é promulgado o Estatuto da Igualdade Racial (Lei 12.2888/2010), que reúne um conjunto de medidas para erradicar o racismo e promover a igualdade racial. Como parte do sistema legal, o Estatuto não ganhou o peso político necessário para promover políticas públicas, garantir direitos e erradicar as diferentes modalidades de discriminação racial, sobretudo aquela que ocorre no âmbito institucional.

Cabe lembrar que em 2015, 100 mil mulheres negras saíram de todos os cantos do país e tomaram a esplanada de Brasília para, outra vez, denunciar o racismo e a violência contra a população negra, em especial contra as mulheres negras, e propor um novo padrão de civilidade

\footnotetext{
${ }^{14}$ Carta de 2008 endereçada por um grupo de 113 intelectuais, sindicalistas, empresários e ativistas de movimentos negros a Gilmar Mendes, então presidente do STF (Supremo Tribunal Federal). Cidadãos Antirracistas Contra as Leis Raciais. Disponível em: https://fundacaofhc.org.br/files/pdf/carta-cidadaos-anti-racistas-contra-as-leis-raciais.pdf. Acesso em: 01 maio 2020.
} 


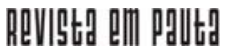

\} RACISMO: CRIMINALIZAÇÃO E GENOCÍDIO - XAVIER, L. \}

DOI: $10.12957 /$ REP.2020.52018

denominado Bem Viver ${ }^{15}$. De 2015 em diante só recrudesceu os ataques contra a população negra.

Nesse breve relato dos esforços políticos empreendidos pelos Movimentos Negros e de Mulheres Negras, nos deparamos com diversas medidas para promover a igualdade racial e mover as barreiras que impedem o efetivo exercício dos direitos para negros e negras. No entanto, as desigualdades raciais permanecem.

Em recente publicação do Instituto Brasileiro de Geografia e Estatísticas (IBGE), sobre as desigualdades sociais por raça/cor, em 2019, alguns indicadores saltam aos olhos. Destes, destaco a representação política de negros na Câmara dos deputados, a taxa de analfabetismo e a distribuição de renda. Segundo o Informativo, negros (pretos e pardos) correspondem a $54 \%$ da população brasileira e ocupam somente $24,4 \%$ das 503 cadeiras da Câmara Federal. O restante é ocupado por 75,6 \% de brancos e outros grupos minoritários.

Em relação a Educação, a taxa de analfabetismo entre negros e brancos, corresponde $9,1 \%$ e $3,9 \%$ respectivamente. No meio urbano a taxa é de $3,9 \%$ para brancos e $6,8 \%$ para negros. Enquanto que no meio rural, a taxa de analfabetismo para brancos é de $11 \%$ e para negros $20,7 \%$. Em 2018, 15,4\% de brancos e 32, 9\% de negros tinham renda inferior a 5,50 USD/dia.; isto é, não conseguiam comer um prato de comida por $\mathrm{dia}^{16}$.

\section{O informativo também ressalta que:}

Em 2018, enquanto 34,6\% das pessoas ocupadas de cor ou raça branca estavam em ocupações informais, entre as de cor ou raça preta ou parda esse percentual atingiu 47,3\%. A maior informalidade entre as pessoas de cor ou raça preta ou parda e o padrão da série, mesmo em 2016, quando a proporção de ocupação informal atingiu seu mínimo. Nesse ano, havia 39,0\% de pessoas ocupadas informalmente, sendo que, entre as pretas ou pardas, tal proporção atingiu 45,6\%" (IBGE, 2019).

Sobre o rendimento médio mensal real: para brancos era de $\mathrm{R} \$$ 2.999; para pardos de $\mathrm{R} \$ 1.719$ e pretos $\mathrm{R} \$ 1.673$. Brancos possuem rendimentos $29,9 \%$ superiores à média nacional ( $R$ \$ 2.308), enquanto pardos e pretos receberam rendimentos $25,5 \%$ e $27,5 \%$, respectivamente, inferiores a essa média em 2019. (IBGE,2020, p.2) ${ }^{17}$.

\footnotetext{
${ }^{15}$ Marcha das Mulheres Negras 2015, contra o Racismo e a Violência e pelo bem viver como nova Utopia. Disponível em: https://www.geledes.org.br/carta-das-mulheres-negras-2015/. Acesso em: 02 jul. 2020.

${ }^{16}$ Desigualdades Sociais por Cor ou Raça no Brasil. Estudos e Pesquisas • Informação Demográfica e Socioeconômica IBGE, n.41, 2019.

${ }^{17}$ Rendimento de todas as fontes 2019.Pesquisa Nacional por Amostra de Domicílios Contínua. IBGE, 2020.
} 
Dentre os dados, os mais sensíveis têm a ver com os homicídios. Segundo o Atlas da Violência ${ }^{18}$, em 2017 foram assassinadas 650.602 pessoas, destas 75,5\% eram negras. Ainda segundo o estudo:

Em 2017, 35.783 jovens foram assassinados no Brasil. Esse número representa uma taxa de 69,9 homicídios para cada 100 mil jovens no país, taxa recorde nos últimos dez anos. Homicídios foram a causa de $51,8 \%$ dos óbitos de jovens de 15 a 19 anos; de 49,4\% para pessoas de 20 a 24; e de 38,6\% das mortes de jovens de 25 a 29 anos; tal quadro faz dos homicídios a principal causa de mortes entre os jovens brasileiros em 2017 (2019, p.25).

Em relação aos homicídios de mulheres negras e não brancas, o estudo apontou crescimento considerável da taxa de homicídios para muIheres negras em 10 anos que:

Enquanto a taxa de homicídios de mulheres não negras teve crescimento de 4,5\% entre 2007 e 2017, a taxa de homicídios de mulheres negras cresceu 29,9\%. Em números absolutos a diferença é ainda mais brutal, já que entre não negras o crescimento é de 1,7\% e entre mulheres negras de 60,5\%.

Após analisar uma pequena parte da trajetória de luta dos Movimentos Negros e de Mulheres Negras por igualdade, face a constante prática genocida contra a população negra, resta-nos perguntar: quando vamos começar a respirar?

\section{À Guisa de Conclusão}

Atravessada pelas crises engendradas pela pandemia do novo Coronavírus (Covid-19) a sociedade brasileira segue tratando a questão racial como um problema intrínseco de um grupo destinado a servir. Olhando ainda para a questão como parte dos processos de empobrecimento causado pelas relações capitalistas. Mesmo quando a população negra brada dizendo que não se trata de classe, raça e gênero como dimensões acumulativas geradoras das desigualdades, e sim interrelacionadas às diferentes intersecções dos processos sociais. Raça é fundante para compreender o modo de nascer, viver e morrer da população negra no Brasil e também para entender por que a sociedade brasileira não quer estender a igualdade para essa população.

No que se refere aos profissionais de Serviço Social, é preciso garantir uma formação crítica, a partir da revisão do conjunto teórico que

\footnotetext{
${ }^{18}$ Atlas da Violência 2019; Anuário Brasileiro de Segurança Pública, ano 13, 2019; Pesquisa Visível e Invisível: a Vitimização de Mulheres no Brasil, 2ª ed., 2019; Índice de Vulnerabilidade Juvenil à Violência 2017; Ministério da Justiça e Segurança Pública: Pesquisa Perfil das Instituições de Segurança Pública 2017.
} 


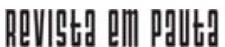

\} RACISMO: CRIMINALIZAÇÃO E GENOCÍDIO - XAVIER, L. \}

DOI: $10.12957 /$ REP.2020.52018

orienta a leitura da realidade e as práticas profissionais. Nesse sentido, a prática profissional precisa trazer para o contexto profissional a dimensão da cidadania como fator estruturante da atenção em políticas públicas dos grupos historicamente excluídos, especialmente quando estes estão em situação de vulnerabilidade. Reafirmar que racismo, sexismo, LGBTIfobias e outras formas de discriminação precisam deixar de ser a base do exercício da democracia, da liberdade e dos direitos humanos.

A democracia não pode ser defendida às custas do genocídio da população negra. Genocídio em curso que aniquila, primeiro, o futuro enquanto simultaneamente aniquila outros de nós. Assassina as vidas antes e durante a sua gestação (morte materna), quando crianças e jovens (morte social e física), quando adultos e idosos (sem condições dignas de vida, encarcerados, com morbidades evitáveis e sem acesso a serviços). Mata também o pensamento, a história e o futuro, quebrando a alma.

A resposta à pergunta quando vamos começar a respirar é óbvia: quando alcançarmos a Igualdade e a Justiça. 


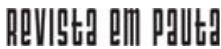

\} RACISMO: CRIMINALIZAÇÃO E GENOCÍDIO - XAVIER, L. \}

DOI: $10.12957 / R E P .2020 .52018$

\section{Referências}

ABREU, R. B. A Marcha Contra a Farsa da Abolição na Transição Democrática (1988). Revista Contemporânea. Dossiê 1964-2014: 50 Anos depois, a cultura autoritária em questão. Ano 4, n. 5, 2005. ISSN: 22364846. Disponível em: http://www.encontro2014.rj.anpuh.org/resources/ anais/28/1393170298_ARQUIVO_AMarchaContraaFarsadaAbo licaonaTransicaoDemocratica.pdf. Acesso em: 01 maio 2020.

BRASIL. Convenção para a Prevenção e Repressão do Crime de Genocídio, 1948. Disponível em: http://pfdc.pgr.mpf.mp.br/atuacao-e-conteudos-deapoio/legislacao/segurancapublica/convenca....crime_genocidio.pdf. Acesso em: 02 jul. 2020.

BRASIL. Decreto $n^{\circ} 30.822$, de 6 de maio de 1952. Promulga a convenção para a prevenção e a repressão do crime de Genocídio, concluída em Paris, a 11 de dezembro de 1948, por ocasião da III Sessão da Assembleia Geral das Nações Unidas. Disponível em: http://www.planalto.gov.br/ ccivil_03/Atos/decretos/1952/D30822.html. Acesso em: 02 jul. 2020.

BRASIL. Decreto Presidencial de 20 de novembro de 1995. Presidência da República, Secretaria-Geral. Subchefia para Assuntos Jurídicos, 1995. Disponível em: http://www.planalto.gov.br/CCIVIL_03/DNN/ Anterior_a_2000/1995/Dnn3531.htm. Acesso em: 02 jul. 2020.

BRASIL. Lei $n^{\circ} 12.288$, de 20 de julho de 2010. Institui o Estatuto da Igualdade Racial. Presidência da República. Casa Civil. Subchefia para Assuntos Jurídicos, 2010.

BRASIL. Atlas da violência 2019. (Orgs.) Instituto de Pesquisa Econômica Aplicada; Fórum Brasileiro de Segurança Pública. Brasília: Rio de Janeiro: São Paulo: Instituto de Pesquisa Econômica Aplicada; Fórum Brasileiro de Segurança Pública, 2019. Disponível em: https://www.ipea.gov.br/ atlasviolencia/download/19/atlas-da-violencia-2019. Acesso em: 02 jul. 2020.

G1. Mesmo com pandemia do coronavírus, Brasil tem alta de $11 \%$ no número de assassinatos em março. Atualizada em 25 de maio de 2020. Monitor da Violência. Globo.com. 2020a. Disponível em: https:// g1.globo.com/monitor-da-violencia/noticia/2020/05/25/mesmo-compandemia-do-coronavirus-brasil-tem-alta-de-11 percent-no-numero-deassassinatos-em-marco.ghtml. Acesso em: 02 jul. 2020.

G1. Sérgio Camargo, presidente da Fundação Palmares, chama movimento negro de 'escória maldita' em reunião. Atualizada em 02 de junho de 2020. Política. Globo.com. 2020b. Disponível em: https://g1.globo.com/politica/ noticia/2020/06/02/sergio-camargo-presidente-da-fundacao-palmares- 


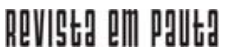

\} RACISMO: CRIMINALIZAÇÃO E GENOCÍDIO - XAVIER, L. \}

DOI: $10.12957 /$ REP.2020.52018

chama-movimento-negro-de-escoria-maldita-em-reuniao.ghtml. Acesso em: 02 jul. 2020.

HENRIQUES, R. Raça e gênero no sistema de ensino: os limites das políticas universalistas na educação. Brasília: UNESCO, 2002. Disponível em: http:/ /www.clam.org.br/bibliotecadigital/uploads/publicacoes/1335_ 609_henriquesricardo.pdf. Acesso em: 02 jul. 2020.

IBGE. Desigualdades Sociais por Cor ou Raça no Brasil. Estudos e Pesquisas. Informação Demográfica e Socioeconômica, n.41, 2019.

PAULINO, R. Ainda a lamentar. 2011. Escultura em cerâmica, cordão, madeira, plástico e metal. Disponível em: http://www.rosanapaulino.com. br/. Acesso em: 02 jul. 2020.

PIRES, T. R. O. Estruturas intocadas: Racismo e ditadura no Rio de Janeiro.

Revista Direito e Práxis 9 (2). Universidade do Estado do Rio de Janeiro, Rio de Janeiro, 2018. Disponível em: https://www.scielo.br/scielo.php?pid= S2179-9662018000201054\&script=sci_arttext\&tlng=pt. Acesso em: 01 maio 2020.

SENADO FEDERAL. Relatório Final da Comissão Parlamentar de Inquérito do Assassinato de Jovens (CPIADJ). Criada pelo Requerimento $\mathrm{n}^{-}$115, de 2015, de autoria da Senadora Lídice da Mata (PSB/BA). Relator: Senador Lindbergh Farias (PT/RJ). Brasília, 2020. Disponível em: https://www12. senado.leg.br/noticias/arquivos/2016/06/08/veja-a-integra-do-relatorio-dacpi-do-assassinato-de-jovens. Acesso em: 02 jul. 2020.

WERNECK, J. A era da inocência acabou, já foi tarde. Ashoka empreendedores sociais, 2003, p. 39-48.

WERNECK, J. A luta continua: O combate ao racismo no Brasil pós-Durban. Revista do Observatório da Cidadania, n. 55, 2005. Disponível em: http:// www.socialwatch.org/sites/ default/files/pdf/en/panorbrasileirod2005 _bra.pdf. Acesso em: 01 maio 2020.

DOI: $10.12957 /$ rep.2020.52018

Recebido em 23 de junho de 2020.

Aprovado para publicação em 29 de junho de 2020.

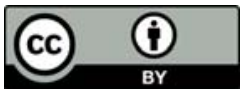

A Revista Em Pauta: Teoria Social e Realidade Contemporânea está licenciada com uma Licença Creative Commons Atribuição 4.0 Internacional. 